\title{
A sociedade da informação e seus desafios
}

Jorge Werthein

$\mathrm{PhD}$ em educação com master em comunicação, Universidade de Stanford. Representante da Unesco no Brasil e coordenador do Programa Unesco - Mercosul.

e-mail: werthein@unesco.org.br

\section{Resumo}

Partindo de um conceito que ressalta as características do novo paradigma técnico econômico e critica as concepções deterministas e evolucionistas da mudança social, apresentam-se as promessas da sociedade da informação que justificam o esforço da sociedade na sua construção. Descontados os exageros utópicos que constituem a "computopia", a justificativa desse esforço prende-se às perspectivas oferecidas pelo novo paradigma de avanços significativos para a vida individual e coletiva, elevando o patamar dos conhecimentos gerados e utilizados na sociedade, oferecendo o estímulo para constante aprendizagem e mudança, facilitando a salvaguarda da diversidade e propiciando dinamismo econômico mais condizente com o respeito ao meio ambiente. Suas promessas não podem impedir a constatação de inúmeros desafios e problemas. Alguns são técnicos, outros de natureza social, outros ainda são puramente econômicos e requerem um compromisso político para assegurar o acesso a comunidades menos privilegiadas. Finalmente, há significativos desafios a enfrentar para criar um arcabouço internacional apropriado que minimize as desigualdades globais no acesso à informação.

\section{Palavras-chave}

Sociedade da Informação; Acesso à informação; Democratização da informação; Tecnologia da informação; Mudança social; Disseminação da informação; Busca da informação.

\section{Information society and its challenges}

\begin{abstract}
The article begins with a discussion of the concept of "information society" that stresses the characteristics of the new techno-economic paradigm and criticises determinism and the evolucionist approach to social change. Discussing the great expectations from the information society, the author explores the reasons for a global effort to be put into its development. Utopian excesses of a "computopia" apart, reasons for building an information society stem from the possibilities it allows for significant advances in individual and social life, raising the level of knowledge produced and put into use in society, stimulating continuous change and learning, helping the recovery and maintenance of diversity and providing a kind of economic dynamism that is more in tune with sound environmental policies. Good promises, satisfactory as they might be, cannot, however, cover up the existence of various problems and challenges. Some of them are technical, while others are of a social nature. Economic challenges will require deep political commitment to guarantee access to the less privileged. Finally, it is a great challenge to build an international framework to minimise global inequalities in information access.
\end{abstract}

\section{Keywords}

Information Society; Access to informação; Democratization of informação; Information technology; Social change; Information dissemination; Information search.

\section{INTRODUÇÃO}

Dificilmente alguém discordaria de que a sociedade da informação é o principal traço característico do debate público sobre desenvolvimento, seja em nível local ou global, neste alvorecer do século XXI. Das propostas políticas oriundas dos países industrializados e das discussões acadêmicas, a expressão "sociedade de informação" transformou-se rapidamente em jargão nos meios de comunicação, alcançando, de forma conceitualmente imprecisa, o universo vocabular do cidadão. Uno-me a todos os que têm procurado desfazer a teia de imprecisões verbais em relação às mudanças do mundo contemporâneo e, desta forma, contribuído para destruir mitos que impedem uma consciente participação nesse processo de mudança. Uma reflexão crítica que permita compreender as presentes transformações sociais e avaliar suas implicações com base em critérios definidos deverá permitir a integração de critérios sócio-culturais e éticos aos econômicos e políticos usualmente associados à prescrição da "sociedade da informação" e, desta forma, colocar à disposição do cidadão caminhos para uma participação ativa na construção de seu futuro.

O ponto de partida nesse artigo é, portanto, definir essa expressão com o rigor possível no espaço que dispomos. Nas seção 3 serão discutidas algumas das promessas da sociedade da informação que justificam o esforço de todos em seu desenvolvimento. As preocupações com a direção que vem tomando o novo paradigma tecnológico da informação concluem o artigo que aponta os inúmeros desafios a enfrentar para que a nova sociedade supere velhas e novas desigualdades.

\section{A “sociedade da informação"}

A expressão "sociedade da informação" passou a ser utilizada, nos últimos anos desse século, como substituto para o conceito complexo de "sociedade pós-industrial" e como forma de transmitir o conteúdo específico do "novo paradigma técnico-econômico". A realidade que os conceitos das ciências sociais procuram expressar referese às transformações técnicas, organizacionais e administrativas que têm como "fator-chave" não mais os insumos baratos de energia - como na sociedade industrial - mas os insumos baratos de informação propiciados pelos avanços tecnológicos na microeletrônica e telecomunicações. Esta sociedade pós-industrial ou 
“informacional”, como prefere Castells, está ligada à expansão e reestruturação do capitalismo desde a década de 80 do século que termina. As novas tecnologias e a ênfase na flexibilidade - idéia central das transformações organizacionais - têm permitido realizar com rapidez e eficiência os processos de desregulamentação, privatização e ruptura do modelo de contrato social entre capital e trabalho característicos do capitalismo industrial.

As transformações em direção à sociedade da informação, em estágio avançado nos países industrializados, constituem uma tendência dominante mesmo para economias menos industrializadas e definem um novo paradigma, o da tecnologia da informação, que expressa a essência da presente transformação tecnológica em suas relações com a economia e a sociedade. Esse novo paradigma tem, segundo Castells (2000) as seguintes características fundamentais:

- A informação é sua matéria-prima: as tecnologias se desenvolvem para permitir o homem atuar sobre a informação propriamente dita, ao contrário do passado quando o objetivo dominante era utilizar informação para agir sobre as tecnologias, criando implementos novos ou adaptando-os a novos usos.

- Os efeitos das novas tecnologias têm alta penetrabilidade porque a informação é parte integrante de toda atividade humana, individual ou coletiva e, portanto todas essas atividades tendem a serem afetadas diretamente pela nova tecnologia.

- Predomínio da lógica de redes. Esta lógica, característica de todo tipo de relação complexa, pode ser, graças às novas tecnologias, materialmente implementada em qualquer tipo de processo.

- Flexibilidade: a tecnologia favorece processos reversíveis, permite modificação por reorganização de componentes e tem alta capacidade de reconfiguração.

- Crescente convergência de tecnologias, principalmente a microeletrônica, telecomunicações, optoeletrônica, computadores, mas também e crescentemente, a biologia. $\mathrm{O}$ ponto central aqui é que trajetórias de desenvolvimento tecnológico em diversas áreas do saber tornam-se interligadas e transformam-se as categorias segundo as quais pensamos todos os processos.
O foco sobre a tecnologia pode alimentar a visão ingênua de determinismo tecnológico segundo o qual as transformações em direção à sociedade da informação resultam da tecnologia, seguem uma lógica técnica e, portanto, neutra e estão fora da interferência de fatores sociais e políticos. Nada mais equivocado: processos sociais e transformação tecnológica resultam de uma interação complexa em que fatores sociais pré-existentes, a criatividade, o espírito empreendedor, as condições da pesquisa científica afetam o avanço tecnológico e suas aplicações sociais. Vale reproduzir um comentário de Castells:

É provável que o fato da constituição desse paradigma ter ocorrido nos EUA e, em certa medida, na Califórnia e nos anos 70, tenha tido grandes conseqüências para as formas e a evolução das novas tecnologias da informação. Por exemplo, apesar do papel decisivo do financiamento militar e dos mercados nos primeiros estágios da indústria eletrônica, da década de 40 à de 60 , o grande progresso tecnológico que se deu no início dos anos 70 pode, de certa forma, ser relacionado à cultura da liberdade, inovação individual e iniciativa empreendedora oriunda da cultura dos campi norte-americanos da década de $60 .$. . Meio inconscientemente, a revolução da tecnologia da informação difundiu pela cultura mais significativa de nossas sociedades o espírito libertário dos movimentos dos anos 60. (Castells, 2000, pp.25)

Além do indevido determinismo, incorre-se muitas vezes também em despropositado evolucionismo na discussão do novo paradigma tecnológico quando a "sociedade da informação" é vista como etapa de desenvolvimento. Como muito bem alerta Agudo Guevara (2000), melhor seria referir-se a sociedades da informação, no plural, para identificar, numa dimensão local, aquelas nas quais as novas tecnologias e outros processos sociais provocaram mudanças paradigmáticas. A expressão "sociedade da informação", no singular, seria melhor utilizada, numa dimensão global (ou mundial), para identificar os setores sociais, independente de sua ubicação local, que participam "como atores de processos produtivos, de comunicação, políticos e culturais que têm como instrumento fundamental as TIC [tecnologias de informação e comunicação] e se produzem - ou tendem a produzir-se - em âmbito mundial" (Agudo Guevara, 2000, pp.4).

O determinismo e o evolucionismo distorcem a análise do complexo processo de mudança social e alimentam uma atitude passiva, contemplativa, em relação a esse processo. Tais posturas impedem ou ignoram que a sociedade, especialmente por intermédio do Estado, tem 
desempenhado, no decorrer da história, um papel muito ativo tanto para promover quanto para sufocar o desenvolvimento tecnológico e suas aplicações sociais. Isso é particularmente claro no que se refere às novas tecnologias. $\mathrm{O}$ avanço tecnológico no novo paradigma foi em grande parte o resultado da ação do Estado e é o Estado que está à frente de iniciativas que visam ao desenvolvimento da "sociedade da informação" nas nações industrializadas e em muitas daquelas que ainda estão longe de ter esgotado as potencialidades do paradigma industrial.

Adotando a sugestão de Agudo Guevara, um olhar sobre a experiência concreta das sociedades de informação permite revelar como a reestruturação do capitalismo e a difusão das novas tecnologias da informação lideradas e/ ou mediatizadas pelo Estado estão interagindo com as forças sociais locais e gerando um processo de transformação social. Em termos gerais, é consenso entre analistas que a realização do novo paradigma se dá em ritmo e atinge níveis díspares nas várias sociedades. Junto com o jargão da "sociedade da informação" já é lugar comum a distinção entre países e grupos sociais "ricos" e "pobres" em informação. As desigualdades de renda e desenvolvimento industrial entre os povos e grupos da sociedade reproduzem-se no novo paradigma. Enquanto, no mundo industrializado, a informatização de processos sociais ainda tem de incorporar alguns segmentos sociais e minorias excluídas, na grande maioria dos países em desenvolvimento, entre eles os latino-americanos, vastos setores da população, compreendendo os médios e pequenos produtores e comerciantes, docentes e estudantes da área rural e setores populares urbanos, adultos, jovens e crianças das classes populares no campo e na cidade, além daquelas populações marginalizadas como desempregados crônicos e os "sem-teto" engrossam a fatia dos que estão ainda longe de integrar-se no novo paradigma (Agudo Guevara 2000). Este fato fundamental constitui um dos desafios éticos para a constituição das sociedades da informação, desafio que somente a ação social consciente poderá superar, já que certamente não será resolvido pelo avanço tecnológico em si mesmo, nem por uma hipotética evolução natural.

\section{AS PROMESSAS DO NOVO PARADIGMA}

Por que é desejável promover a sociedade da informação?

Passadas as primeiras reações de temor diante dos efeitos da automação dos setores produtivos, os avanços da informática e da telemática provocaram uma fase de fascinação quase infantil - felizmente em grande parte já superada - particularmente nas três últimas décadas, quando a difusão da Internet nos países industrializados deu suporte ao sonho de integração mundial dos povos por meio de infovias globais. Embora o realismo de estudos e análises tenha, desde aquela época, contrabalançado o entusiasmo ingênuo, há que reconhecer como em grande parte justificadas as bases e evidências que fundamentam especulações positivas sobre a sociedade da informação.

Utilizando as características do novo paradigma técnicoeconômico descrito na seção anterior, pode-se destacar justificadas expectativas positivas sobre a sociedade da informação. Em primeiro lugar, a substituição de insumos baratos de energia por informação como fator-chave do novo paradigma representa, para a sociedade, uma saída inesperada para a questão estrutural da degradação do meio ambiente.

Se a penetrabilidade das novas tecnologias pode, por um lado, elevar o temor com possíveis efeitos negativos - a serem analisados na próxima seção - e até reforçar a inevitabilidade das transformações que acarreta, por outro lado fundamenta a concepção da sinergia capaz de conferir dinamismo ao processo de mudança desde que deflagrado, reforça a idéia da impossibilidade de integração "parcial" ao novo paradigma e dá suporte às iniciativas que visam preparar a sociedade como um todo para enfrentar e tomar partido das tendências de transformações técnicoeconômicas.

Porque permite implementar materialmente a lógica de redes, a tecnologia permite modelar resultados imprevisíveis da criatividade que emana da interação complexa, desafio quase intransponível no padrão tecnológico anterior. Se isso dá vazão aos sonhos mais delirantes no âmbito das ciências básicas, das aplicações tecnológicas avançadas e da estratégia, não deixa também de alimentar sonhos mais prosaicos - e não menos significantes - como o de finalmente permitir a integração ensino/aprendizagem de forma colaborativa, continuada, individualizada e amplamente difundida.

A flexibilidade que caracteriza a base do novo paradigma é, talvez, o elemento que mais fortemente fundamenta as especulações positivas da sociedade da informação. É ela que incorpora, na essência do paradigma, a idéia de "aprendizagem". A capacidade de reconfiguração do sistema refere-se a maior disponibilidade para a incorporação da mudança. A noção de "aprendizagem" passa a ser empregada em vários níveis, sendo o organizacional sua aplicação de maior significado na reestruturação capitalista no novo paradigma. 
Obviamente, a flexibilidade também dá fundamento às expectativas de contínua adaptação de trabalhadores e consumidores, produtores e usuários, o que coloca o contínuo aperfeiçoamento intelectual e técnico como requisito da sociedade da informação.

A convergência tecnológica reforça os efeitos da sinergia decorrente da penetrabilidade das tecnologias na sociedade da informação. Daí é fácil compreender a fascinação (e o temor) com uma utópica sociedade informatizada em que não apenas o desenvolvimento tecnológico parece não ter limites nem desacelerar e, dessa forma, alterar continuamente todos os processos que afetam a vida individual e coletiva. Se a corrida espacial frustrou a imaginação popular de viagens interplanetárias ao alcance de todos no século XXI, os avanços da telemática e da microeletrônica prometem colocar ao alcance da mão facilidades nunca antes imaginadas em termos de bemestar individual, lazer e acesso rápido, ilimitado e eficiente, ao rico acervo do conhecimento humano.

As características do novo paradigma justificam, para alguns analistas, a crença de que a sociedade da informação será completamente diferente da sociedade industrial e que podemos aguardar para breve a "computopia", bastando que compreendamos e direcionemos as forças sociais subjacentes.

Uma formulação dessa visão idealizada é a de Masuda (1985), autor do Plano Japonês para uma Sociedade da Informação publicado nos anos 70. Nessa utopia, a tecnologia dos computadores terá como função fundamental substituir e amplificar o trabalho mental dos homens; permitirá a produção em massa de conteúdo cognitivo, informação sistematizada, tecnologia e conhecimento. A infra-estrutura pública de computadores articulados em redes e bancos de dados substituirá os centros de produção de bens como símbolo societário. A elevação da capacidade educacional e técnica e de criação de novas oportunidades econômicas terão o papel desempenhado pela descoberta de novos continentes e aquisição de colônias na expansão do mercado da sociedade industrial. A liderança da economia será ocupada pela indústria intensiva em conhecimento. A produção de informação pelo próprio usuário ganhará grande espaço e importância na estrutura econômica. O mais relevante sujeito de ação social será a comunidade de voluntários, não a empresa ou grupos econômicos, e a sociedade não será hierárquica, mas multicentrada, complementar e de participação voluntária. A meta social será a concretização do valor do tempo e não mais a criação de uma sociedade de alto bem-estar. A democracia participativa substituirá o sistema parlamentar e a regra da maioria e os movimentos sociais serão a força por trás de mudanças sociais. Em seu estágio avançado, será uma sociedade de criação de conhecimento. O globalismo, a harmonia entre homem e natureza, a auto-disciplina e a contribuição social serão os princípios orientadores dessa sociedade (Masuda 1985: 620-625).

Embora o desenvolvimento nas sociedades da informação tenha logo mostrado os exageros de uma tal utopia, traços semelhantes são ainda encontrados em formulações que procuram antecipar a direção das transformações sociais em curso. É curiosa, por exemplo, a especulação de Tiffin e Rajansingham sobre as perspectivas que as novas tecnologias oferecerão no campo da educação.

Os autores chamam a atenção para a sala de aula como um "sistema de comunicação que torna possível a um grupo de pessoas encontrar-se para falar sobre algo que desejam aprender, ver figuras e diagramas e ler textos que as ajudem a compreender. Numa sala de aula convencional isto é tornado possível pelas paredes que dão proteção contra o barulho e interferência externos de forma que, aqueles que estão dentro da sala, podem ouvir e ver uns aos outros e também, no quadro-negro, as palavras, diagramas e figuras sobre o assunto que está sendo aprendido. A questão é, pode a tecnologia da informação fornecer um sistema de comunicação alternativo que seja pelo menos tão eficiente quanto a sala de aula convencional?"(Tiffin e Rajansingham, 1995, p.6) A realidade de muitos países justifica uma resposta afirmativa: vários pontos remotros podem ser conectados graças à telemática em teleconferência nas "salas de aula virtuais" seja sob a forma audiográfica mais simples ou em videoconferências.

A emergência da tecnologia da realidade virtual (RV), na década de 90 , levou a previsões quase ficcionais da revolução no processo de educação.

A RV oferece-nos a possibilidade de uma turma encontrar-se na Floresta Amazônica ou no topo do Monte Everest; poderá permitir-nos expandir nossa perspectiva de observação até ver o sistema solar operando como um jogo de bolas de vidro à nossa frente, ou encolhê-la de forma a poder caminhar em meio à estrutura atômica como se ela fosse uma escultura num parque; poderemos entrar na realidade virtual ficcional no papel de um personagem de uma peça, ou na realidade virtual não ficcional para acompanhar um cirurgião na exploração microscópica do corpo humano. Usaremos essa extraordinária tecnologia para fazer avançar o modo pelo qual aprendemos, ou a utilizaremos para criar versões virtuais de salas de aula convencionais? (Tiffin e Rajansingham, 1995, pp 7 e 8). 
Em sua especulação, Tiffin e Rajansingham imaginam "Shirley", a "aprendiz autônoma" da futura sociedade da informação, vestida em sua roupa digital e com seu capacete ajustado, assistindo Laurence Olivier interpretar Hamlet num velho filme preto e branco, uma atividade do curso "Encenação de Peças de Shakespeare". Comparando as diferenças entre a encenação do filme com a teatral, ela se indaga sobre como teria sido a encenação original. Onde era Elsinore?

"Pare", ela diz, e o filme mantém a imagem da amurada na abertura da cena do fantasma. "Mapeie", ela pede, e depois, "Mostre a Dinamarca". Em seguida, ordena "Busque Elsinore" e... lá está, exatamente onde a Dinamarca e a Suécia se defrontam, separadas por uma faixa de água. "Deve ter sido uma posição muito estratégica", pensa e vê que o nome em dinamarquês era Helsingor. Com o dedo, circula Elsinore e, então diz, "Mostre”, e lá está a vila com o terminal do barco de transporte e, numa península ao lado do porto, o castelo. Em seguida, ela circula o castelo e recebe uma planta baixa de todo o terreno e edificações. Neste ponto, entretanto, uma janela abre-se num dos lados do plano com os seguintes dizeres: "Castelo de Helsingor, Informação Proprietária do Governo Dinamarquês. Serviços de informação disponíveis. Todos os principais cartões de crédito são aceitos'... (Tiffin e Rajansingham, 1995, pp.145).

Apesar das limitações impostas pela apropriação da informação relevante, a especulação dos autores nos garante que Shirley consegue "entrar" no castelo e percorrer os lugares correspondentes às referências feitas em Hamlet, à medida que a peça é virtualmente encenada, escolhendo ora a posição de "platéia", ora de ator...

Sem precisar recorrer a formulações utópicas como as representadas pelas especulações de Masuda ou Tiffin e Rajansingham, a reflexão sobre as potencialidades do novo paradigma permite responder à pergunta que inicia esta seção. É desejável promover a sociedade da informação porque o novo paradigma oferece a perspectiva de avanços significativos para a vida individual e coletiva, elevando o patamar dos conhecimentos gerados e utilizados na sociedade, oferecendo o estímulo para constante aprendizagem e mudança, facilitando a salvaguarda da diversidade e deslocando o eixo da atividade econômica em direção mais condizente com o respeito ao meio ambiente.

\section{DESAFIOS NA CONSTRUÇÃO DE SOCIEDADES DA INFORMAÇÃO}

Exageros especulativos à parte, é preciso reconhecer que muitas das promessas do novo paradigma tecnológico foram e estão sendo realizadas, particularmente no campo das aplicações das novas tecnologias à educação. Educação à distância, bibliotecas digitais, videoconferência, correio eletrônico, grupos de "bate-papo", e também voto eletrônico, banco on-line, video-on-demand, comércio eletrônico, trabalho à distância, são hoje parte integrante da vida diária na maioria dos grandes centros urbanos no mundo.

A satisfação com tais avanços, no entanto, não deve impedir-nos de identificar áreas de preocupação com a direção e o ritmo da mudança. A sociedade vem observando com atenção a evolução histórica do novo paradigma da informação e externando, em cada etapa desse desenvolvimento, suas preocupações reais ou infundadas com as implicações sociais das novas tecnologias. Independentemente de aceitarmos ou não a concepção da "neutralidade" ou "ambivalência" da tecnologia, não se pode ignorar as questões éticas relacionadas a ela.

Os desafios da sociedade da informação são inúmeros e incluem desde os de caráter técnico e econômico, cultural, social e legal, até os de natureza psicológica e filosófica. Alguns autores, como Leal (1996) chegam a formular os desafios éticos da sociedade da informação em termos de uma múltipla perda: perda de qualificação, associada à automação, e desemprego; de comunicação interpessoal e grupal, transformada pelas novas tecnologias ou mesmo destruída por elas; de privacidade, pela invasão de nosso espaço individual e efeitos da violência visual e poluição acústica; de controle sobre a vida pessoal e o mundo circundante; e do sentido da identidade, associado à profunda intimidação pela crescente complexidade tecnológica. Já outros, como Brook e Boal (1995) dedicamse a examinar estratégias de resistência para, como um novo "luddismo", lutar contra os aspectos perniciosos da tecnologia virtual acusada de disseminar na sociedade a utilização de um simulacro de relacionamento como substituto de interações face a face e contra a alegada usurpação pelo capital do direito de definir a espécie de automação que desqualifica trabalhadores, amplia o controle gerencial sobre o trabalho, intensifica as atividades e corrói a solidariedade.

Algumas das preocupações acima têm sido transformadas com o avanço do novo paradigma, incluindo as ações dos movimentos sociais em reação às implicações consideradas socialmente inaceitáveis. O desemprego tecnológico e a 
desqualificação do trabalho, por exemplo, tendem a ser contrabalançados pelo próprio aprofundamento das transformações do paradigma o que inclui uma reestruturação sistêmica do emprego e a requalificação dos trabalhadores. Em alguns outros casos, como a perda da privacidade, a sociedade tem-se mobilizado para promover o que Leal identifica como o "comportamento normal responsável” inclusive por meio de legislação adequada para proteger os direitos do cidadão na era digital. A perda do sentimento de controle sobre a própria vida e a perda da identidade são temas que continuam preocupantes e que estão ainda por merecer estratégias eficientes de intervenção.

Uma questão ética do novo paradigma não discutida por analistas como Leal, Brook e Boal diz respeito ao aprofundamento de desigualdades sociais, desta vez, sobre o eixo do acesso à informação. $O$ ritmo do avanço tecnológico no alvorecer do novo paradigma tem sido, sob qualquer ótica, extraordinário. O ritmo de expansão da Internet no mundo levou apenas um terço do tempo que precisou o rádio para atingir uma audiência de 50 milhões de pessoas (Quéau, 1999). A redução dos preços dos computadores por volume de capacidade de processamento facilitou grandemente essa difusão, mas não permitiu ainda superar a relação entre nível de renda e acesso às novas tecnologias. Os dados a seguir ilustram o contraste em relação ao acesso à informação pelas populações de países industrializados e em desenvolvimento.

Dispondo de uma população algumas vezes maior, os baixos níveis de renda per capita nos países em desenvolvimento refletem-se em alta taxa de analfabetismo adulto, baixo acesso à educação formal avançada e à tecnologia da informação tanto convencional quanto moderna.

O nível de agregação dos dados anteriores esconde diferenças importantes dentro do mundo em desenvolvimento, mas mesmo para o terço mais avançado dentre eles, aplica-se a advertência de Mansell e Wehn (1998, capítulo 13) para os quais o papel das tecnologias de informação na construção de uma "sociedade do conhecimento" inovadora poderá ser muito relevante e contribuir para o desenvolvimento sustentado, mas será acompanhado de muitos riscos. Nesses países, em especial os de nível médio de renda - grupo em que se enquadram muitos dos países da América Latina e Caribe - as novas tecnologias e seu uso requerem investimentos na elevação das capacidades tecnológicas locais e no desenvolvimento das instituições políticas, culturais, econômicas e sociais. $\mathrm{O}$ avanço do

\begin{tabular}{|c|c|c|}
\hline Indicadores & $\begin{array}{c}\text { Países } \\
\text { industrializados }\end{array}$ & $\begin{array}{c}\text { Países } \\
\text { em desen- } \\
\text { volvimento }\end{array}$ \\
\hline População estimada, milhões (1995) & $1.228,7$ & $4.538,7$ \\
\hline Produto Interno Bruto per capita (US\$) & 18.158 & 1,141 \\
\hline $\begin{array}{l}\text { Taxa estimada de analfabetismo } \\
\text { adulto como \% da população (1995) }\end{array}$ & 1,3 & 29,6 \\
\hline Matrícula de terceiro grau, milhões (1995) & 18,0 & 4,3 \\
\hline $\begin{array}{l}\text { Estimativa de linhas telefônicas/1000 } \\
\text { habitantes (1995) }\end{array}$ & 424 & 45 \\
\hline $\begin{array}{l}\text { Estimativa de assinantes de telefone } \\
\text { celular/100 habitantes (1995) }\end{array}$ & 91,7 & 5,8 \\
\hline Aparelhos de TV/100 habitantes (1996) & 524 & 145 \\
\hline Computadores pessoais/1000 habitantes (1996) & 156,3 & 6,5 \\
\hline Servidores de Internet, milhares (1996) & 15.818 & 435 \\
\hline $\begin{array}{l}\text { Estimativa de usuários Internet/1000 } \\
\text { habitantes, } 1996\end{array}$ & 17,9 & 0,5 \\
\hline
\end{tabular}

Fonte: Unesco World Communication and Information 1999-2000 Report, pagina 281

novo paradigma dependerá de como serão resolvidas as tensões entre as culturas e modos de organização social existentes e aquelas que começam a se tornar dominantes. As sociedades desses países terão de adaptar suas estruturas institucionais para tratar questões importantes como a proteção da propriedade intelectual. Terão também de examinar a conveniência de estabelecer um equilíbrio entre suas metas de exportação de produtos e serviços de maior conteúdo tecnológico com a criação de oportunidades para ampliar a adoção local das novas tecnologias. Para Mansell e Wehn, "não se pode esperar de estratégias visando acelerar a difusão do novo paradigma que erradiquem a pobreza, em curto prazo, e há riscos de que as novas políticas e investimentos nas aplicações das tecnologias de informação introduzam novas forças de exclusão" (pp.258).

Na sociedade globalizada em que avança o novo paradigma, a emergência de novas forças de exclusão se dá tanto em nível local quanto global e requer esforços em ambos os níveis no sentido de superá-las. Ações fundamentais nessa direção são as que promovem o acesso universal tanto à infra-estrutura quanto aos serviços de informação a preços accessíveis. A conexão internacional dos países em desenvolvimento e até da Europa está extremamente concentrada em poucos pontos de acesso. Como não há a exigência de que os operadores desses pontos de acesso partilhem os custos do circuito completo (até o ponto de acesso internacional e retorno ao ponto de origem), os provedores de serviços de Internet nos países em desenvolvimento devem, na maioria das vezes, pagar pelos custos totais das ligações nos dois sentidos, o que encarece o serviço e restringe suas possibilidades de expansão 
(Quéau, 1999). Novas parcerias e políticas de cooperação internacional deverão ser elaboradas para estimular o desenvolvimento e fortalecimento de redes intraregionais. A instalação de backbones regionais de alta capacidade, por exemplo, permitiria ligar cada país a uma rede global de múltipla conexão onde ninguém dominaria a conectividade.

O acesso universal ao conteúdo e a fontes de conhecimento aponta para a necessidade de resolver vários outros desafios. Um dos mais relevantes, como apontam Mansell e Wehn, é o reconhecimento dos direitos de propriedade intelectual. Do ponto de vista dos países em desenvolvimento, uma delicada negociação com os editores deveria permitir a extensão da legislação relativa ao "uso justo" aos recursos disponíveis na Internet. A essa negociação dever-se-ia acrescentar ações visando difundir de forma eficiente princípios "info-éticos" em relação aos direitos de propriedade intelectual, inclusive na Internet. Uma outra questão é elevar o volume de informação de qualidade e de domínio público disponível na Internet no(s) idioma(s) de expressão da população de cada sociedade. Isso envolverá convencer o governo e centros produtores de conhecimento financiados por recursos públicos a tornarem disponíveis ao público as informações produzidas.

No campo educacional dos países em desenvolvimento, decisões sobre investimentos para a incorporação da informática e da telemática, implicam também riscos e desafios. Será essencial identificar o papel que essas novas tecnologias podem desempenhar no processo de desenvolvimento educacional e, isso posto, resolver como utilizá-las de forma a facilitar uma efetiva aceleração do processo em direção a educação para todos, ao longo da vida, com qualidade e garantia de diversidade. As novas tecnologias de informação e comunicação tornam-se, hoje, parte de um vasto instrumental historicamente mobilizado para a educação e aprendizagem. Cabe a cada sociedade decidir que composição do conjunto de tecnologias educacionais mobilizar para atingir suas metas de desenvolvimento.

O fluxo de informação e da transformação dessa informação em conhecimento está no âmago do mandato da Unesco de contribuir para a paz e segurança por meio da promoção da colaboração entre as nações. Os benefícios da participação na sociedade global da informação requer um consenso internacional dentro deste amplo mandato. O progresso da educação, ciência e cultura é fundamentalmente o de compartilhar informação e de criar novos meios de aprendizagem e conhecimento.
Em decorrência de seu mandato, a Unesco tem atuado de forma sistemática no sentido de apoiar as iniciativas dos Estados Membros na definição de políticas de integração das novas tecnologias aos seus objetivos de desenvolvimento. Na Unesco, o Programa Geral de Informação (PGI) e o Programa Intergovernamental de Informática (IIP), hoje fundidos no Programa Informação para Todos, enfeixavam as ações desse organismo internacional em duas áreas principais, conteúdo para a sociedade da informação e "infoestrutura" para esta sociedade em evolução, por meio da cooperação para treinamento, apoio ao estabelecimento de políticas de informação e promoção de conexões em rede.

No espírito da Declaração Universal dos Direitos do Homem que constitui a base dos direitos à informação na sociedade da informação, e levando em consideração os valores e a visão delineados anteriormente, o novo Programa Informação para Todos deverá prover uma plataforma para a discussão global sobre acesso à informação, participação de todos na sociedade da informação global e as conseqüências éticas, legais e societárias do uso das tecnologias de informação e comunicação. Deverá prover também a estrutura para colaboração internacional e parcerias nessas áreas e apoiar o desenvolvimento de ferramentas comuns, métodos e estratégias para a construção de uma sociedade de informação global e justa.

\section{REFERÊNCIAS BIBLIOGRÁFICAS}

1. AGUDO GUEVARA, Alvaro. Etica en la Sociedad de la Informacion: reflexiones desde America Latina. In: SEMINARIO INFOETICA, 2000, Rio de Janeiro. [s. 1. : s. n., 2000?].

2. BROOK, James, BOAL, Iain A. Resisting the virtual life: the culture and politics of information. San Francisco : City Lights, 1995.

3. CASTELLS, Manuel. A era da informação: economia, sociedade e cultura. In: A Sociedade em rede. São Paulo: Paz e Terra, 2000. v. 1.

4. LEAL, Fernando. Ethics is fragile: goodness is no. In: KARAMJIT, S. Gill. (Ed.). Information Society: new media, ethics and postmodernism. London : Springer, 1996.

5. MANSELL, Robin, WEHN, Uta. Knowledge societies: information technologies for sustainable development. Oxford : Oxford University, 1998.

6. MASUDA, Yoneji. Computopia. In: FORESTER, Tom. (Ed.). The information technology revolution. Oxford : Basil Blackwell, 1985.

7. QUÉAU, Philippe. Including the excluded: for the common good of all. In: TASKNET CONFERENCE, 1999, Nova Delhi, Índia. [s. 1. : s. n., 1999?]

8. TIFFIN, John, RAJASINGHAM, Lalita. In: Search for the virtual class: education in an Information Society. London : Routledge, 1995.

9. UNESCO. (Paris). World communication and information 1999-2000 report. Paris, 1999. 